Fetal Diagnosis and Therapy
Fetal Diagn Ther 2017;41:161-178

DOI: $10.1159 / 000452218$
Received: August 12, 2016

Accepted after revision: October 4, 2016

Published online: February 21, 2017

\title{
Establishing Prenatal Surgery for Myelomeningocele in Asia: The Singapore Consensus
}

\author{
Tuangsit Wataganara $^{a}$ Suresh Seshadri ${ }^{d}$ Tak Yeung Leung ${ }^{\mathrm{e}}$ Citra Matter $^{\mathrm{f}}$ \\ Monawat Ngerncham ${ }^{b}$ Namtip Triyasunant ${ }^{c}$ Padmakar Vidyadhar Mali 9 \\ Agnhitori Biswas $^{\text {h }}$ Katika Nawapun $^{\text {a Nisarat Phithakwatchara }}{ }^{\text {a }}$ Alan W. Flake ${ }^{\mathrm{i}}$ \\ Mark P. Johnson ${ }^{j}$ Arijit Biswas $^{f}$ Mahesh Choolani $^{f}$ \\ ${ }^{a}$ Division of Maternal Fetal Medicine, Department of Obstetrics and Gynecology, ${ }^{b}$ Division of Pediatric Surgery, \\ Department of Surgery, and ' Department of Anesthesiology, Faculty of Medicine Siriraj Hospital, Bangkok, \\ Thailand; dMediscan, Chennai, India; e Department of Obstetrics and Gynecology, Chinese University of Hong Kong, \\ Hong Kong, SAR, China; ${ }^{f}$ Department of Obstetrics and Gynecology, ${ }^{9}$ Division of Pediatric Surgery, Department \\ of Surgery, and hivision of Neonatology, Department of Pediatrics, Yong Loo Lin School of Medicine, National \\ University of Singapore, Singapore; i Children's Center for Fetal Research, and ${ }^{\mathrm{j} C e n t e r}$ for Fetal Diagnosis and \\ Treatment, Children's Hospital of Philadelphia, University of Pennsylvania School of Medicine, Philadelphia, PA, USA
}

\section{Keywords}

Myelomeningocele $\cdot$ Prenatal surgery $\cdot$ Prenatal fetal therapy $\cdot$ Fetal therapy centers

\begin{abstract}
Objectives: The Management of Myelomeningocele Study (MOMS Trial) has inspired many fetal therapy centers (FTCs) to offer open fetal surgery for myelomeningocele (MMC). This is an initial effort to create a candidate model that can be applicable to many parts of Asia. Material and Methods: A limited selection of specialists from 4 established FTCs in Thailand, Hong Kong, India, and Singapore met for a round table discussion. Experts from Children's Hospital of Philadelphia (CHOP) involved in the Trial moderated the session. The practice suggestions in this statement were from a targeted literature review and expert opinion. Results: A high
\end{abstract}

\section{KARGER}

(C) 2017 S. Karger AG, Basel

E-Mail karger@karger.com

www.karger.com/fdt prevalence of MMC in Asia supports an effort to adopt the procedure, but only in established FTCs with good maternal and neonatal ancillary supports. The falling incidence of MMCs may affect case volume and maintenance of skill. A regional approach was recommended. Fetal benefits have to be weighed against maternal risks, with a consideration of recent outcome data from the endoscopic approach. Responsible FTCs need standardized diagnosis and management, with their long-term outcome data available for an audit. Conclusions: It is envisaged that the information presented by this multidisciplinary team would be useful for FTCs in Asia or elsewhere that plan to establish more advanced fetal care in the future.

(c) 2017 S. Karger AG, Basel

Mahesh Choolani, MBBS, MMED, FRCOG, PhD

Department of Obstetrics and Gynaecology, Yong Loo Lin School of Medicine

National University of Singapore, Level 12 NUHS Tower Block

$1 \mathrm{E}$ Kent Ridge Road, Singapore 119228 (Singapore)

E-Mail mahesh_a_choolani@nuhs.edu.sg

Tuangsit Wataganara, MD

Division of Maternal Fetal Medicine, Department of Obstetrics and Gynecology Faculty of Medicine Siriraj Hospital

2 Prannok Road, Bangkok 10700 (Thailand)

E-Mail twataganara@yahoo.com 


\section{Introduction and Objectives}

The publication of the MOMS (Management of Myelomeningocele Study) Trial was a landmark event for the Maternal-Fetal-Neonatal-Pediatric community [1]. It answered many important questions, and raised many more - including the debate between specialists looking after children with myelomeningocele (MMC)-associated physical disability and obstetricians who prioritize maternal safety. The MOMS Trial showed that prenatal repair of MMC (1) decreased the need for ventriculoperitoneal shunting from 82 to $40 \%$, (2) reversed hind brain herniation (Chiari 2 malformation), (3) improved motor function of the lower extremities, and (4) improved the composite score for mental development and motor function and achieved higher rates of independent ambulation at 30 months of age [2]. Accrued benefits from prenatal surgery compared with standard postnatal repair were so significant that in utero MMC repair through an open hysterotomy has become standard of care in some centers. However, the study also showed that this procedure was associated with significant obstetrical complications and higher maternal and fetal risks including: (1) preterm labor and birth, (2) neonatal respiratory distress syndrome, and (3) maternal morbidities such as pulmonary edema, placental abruption, transfusion at the time of delivery, and thinning or dehiscence of the uterine hysterotomy scar.

A round table discussion was held on the last day of the 2nd Asia Pacific Conference on Fetal Therapy (APCFT) in Singapore (April, 2016). The discussion involved local specialists from 4 established fetal therapy centers (FTCs) in Thailand, Hong Kong, India, and Singapore that were also the organizing members of the APCFT. The authors would like to emphasize that the selection of discussants was limited from only a few FTCs in Asia, and thus cannot speak for the entire continent. There was an urging issue that some FTCs may have started to offer this novel treatment to their patients without adequate prior experience and training. Whereas this move would provide for broader access of in utero MMC repair, it also raises concerns about quality assurance and transparent reporting of procedure-related maternal and fetal morbidities. Owing to the relative rarity of MMC in comparison with other malformations, and the limited resources in most parts of Asia, the best strategy may be to address Asia as a single locale (a regional approach). This could allow for case pooling and reasonable resource allocation. This convention was an initial effort to create a candidate model that can be applicable to many parts, but not all, of Asia. We hope that it can also be utilized in other parts of the world with similar social and cultural backgrounds.

The primary objective of this initiative was to develop practical stepwise protocols for adopting this novel fetal therapeutic procedure. Available literature was used to guide the drafting of the protocols and to steer the discussion on the potential impacts of in utero MMC repair at regional level. Patterns of medical practice, socioeconomic differences of countries in Asia, and training requirements in individual countries were provided by regional experts. The secondary objective was to propose a framework for FTCs to offer open fetal surgery such that these could be introduced in a responsible fashion. The data presented herein have been collated from the literature, and are the combined opinions of a selected group of content experts. As such, this article represents initial insights into this new, important and rapidly developing field of medicine, but cannot be viewed as rigid guidelines for the regional countries to necessarily follow.

\section{Materials and Methods}

This primary initiative was designed as a panel assembly of 12 specialists affiliated with 4 established FTCs in Asia, including (1) Faculty of Medicine Siriraj Hospital, Thailand (T.W., M.N., N.T., K.N., and N.P.), (2) Chinese University of Hong Kong, SAR, China (T.Y.L.), (3) Mediscan, India (S.S.), and (4) National University of Singapore, Singapore (C.M., P.V.M., Ag.B., Ar.B., and M.C.). The panel included specialists in maternal-fetal medicine, neonatology, pediatric surgery, neurosurgery, and anesthesiology. The format was a round table discussion in which regional and domain experts in interlacing fields of fetal therapy could freely exchange ideas as how to most appropriately adopt in utero MMC repair in Asia. The panel discussion was part of the 2nd Asia Pacific Conference on Fetal Therapy (APCFT) held in Singapore in April 2016. Two experts (A.W.F. and M.P.J.) from the Children's Hospital of Philadelphia (CHOP), USA, facilitated the dialogue and provided valuable insight from their extensive experience in setting up and offering this service in USA. The primary and secondary objectives were made known to the panelists ahead of the meeting, and a questionnaire (Appendix 1) had been distributed prior to the meeting date.

The protocol of prenatal evaluation and treatment of a fetus with MMC currently used at CHOP was used as an ideal blueprint during the discussion. This CHOP-standardized protocol consists of 3 parts: (1) prenatal evaluation and management of a fetus with MMC; (2) intraoperative management of open repair of fetal MMC; and (3) postoperative management after open surgical repair for fetal MMC. This CHOP care plan is summarized in Appendices $2-4$.

Five key issues influencing adoption of in utero repair of MMC were addressed in a stepwise manner to come up with a preliminary consensus of an adoption protocol that is agreeable by at least all the members of these 4 representative FTCs. Strengths and disadvantages of each Asian country in relation to these issues were reviewed from the medical literature and discussed for an effective
162

Fetal Diagn Ther 2017;41:161-178

DOI: $10.1159 / 000452218$
Wataganara et al. 
Table 1. List of countries in Asia according to the World Health Organization (WHO) regional task force

\begin{tabular}{|c|c|c|c|}
\hline Region & Population & $\begin{array}{l}\text { Member } \\
\text { states }\end{array}$ & Lists (alphabetical order) \\
\hline Western Pacific & 1.8 billion & 37 & $\begin{array}{l}\text { American Samoa, Australia, Brunei Darussalam, Cambodia, China, Cook Islands, Fiji, } \\
\text { French Polynesia (France), Guam (USA), Hong Kong (China), Japan, Kiribati, Lao People's } \\
\text { Democratic Republic, Macao (China), Malaysia, Marshall Islands, Federated States of } \\
\text { Micronesia, Mongolia, Nauru, New Caledonia (France), New Zealand, Niue, } \\
\text { Commonwealth of the Northern Mariana Islands, Palau, Papua New Guinea, Philippines, } \\
\text { Pitcairn Islands (UK), Republic of Korea, Samoa, Singapore, Solomon Islands, Tokelau } \\
\text { (New Zealand), Tonga, Tuvalu, Vanuatu, Vietnam, and Wallis and Futuna }\end{array}$ \\
\hline $\begin{array}{l}\text { South-East } \\
\text { Asia }\end{array}$ & 1.8 billion & 11 & $\begin{array}{l}\text { Bangladesh, Bhutan, Democratic People's Republic of Korea, India, Indonesia, Maldives, } \\
\text { Myanmar, Nepal, Sri Lanka, Thailand, and Timor-Leste }\end{array}$ \\
\hline
\end{tabular}

Asia is divided by its geography and level of development into Western Pacific and South-East Asia.

collaboration in the future. This is to ensure that a large-scale adoption can be conducted in a responsible and ethical manner. A clinical standard, minimum requirement and restrictions can be issued from the local professional organization to limit the precipitous expansion of the service. These 5 key issues are as follows:

1. Actual impact of MMC in Asia

2. Appropriate training for in utero repair of $M M C$

3. Established FTC: (3.1) Definition of fetal therapy center; (3.2) Counseling; (3.3) Personnel; (3.4) Developing and maintaining skills for open fetal surgery; and (3.5) Expansion of existing fetal therapy programs (quality assurance and maintenance of the necessary case volume and expertise)

4. Follow-up data: short and long term

5. Regional issues related to adoption of the procedure

\section{Results}

The products of the round table discussion and literature review of regional data in relation to the stepwise approach in adoption of in utero repair of MMC are as follows.

\section{Actual Impact of MMC in Asia}

MMC causes short- and long-term health consequences. The most prevalent health issue occurring in up to $80 \%$ of MMC patients is hydrocephalus requiring ventriculoperitoneal shunt placement and revision [3]. Secondary health issues related to MMC are direct injury to the prenatally exposed spinal cord, scoliosis, seizures, and postnatal loss of function related to shunt malfunction or tethered cord. There is no evidence that MMC patients in Asia have different severity than elsewhere. Indirect evidence of equivalent severity of MMC across ethnic groups comes from a naturalistic study using inquired data from 16 Caucasian, 11 African-American, and 15 Mexican American

Prenatal Myelomeningocele Surgery in Asia adults. The data did not show a significant difference in terms of mobilization and self-catheterization [4].

The worldwide prevalence of neural tube defect (NTD) has been approximately 1 in 1,000 births [5]. One systematic review of over 5,000 births between 1990 and 2014 reported the areas with the highest and lowest prevalence ranges and medians of NTD for each region as follows: (1) Eastern Mediterranean (2.1-124.1;21.9 per 10,000 births); (2) South-East Asian (1.9-66.2; 15.8 per 10,000 births); (3) African (5.2-75.4; 11.7 per 10,000 births); (4) Americas (3.3-27.9; 11.5 per 10,000 births); (5) European (1.3-35.9; 9.0 per 10,000 births); and Western Pacific (0.3-199.4; 6.9 per 10,000 births) [6]. Asian countries ranked as the second highest prevalence of NTD worldwide in this publication. The most recently published systematic review and meta-analysis to address the global birth prevalence of spina bifida found 3,336 citations, which led to the selection of 179 studies eligible for further analysis. Among these, 92 reported on data from North America, 46 from Europe, 31 from Asia, 7 from Australia, 4 from South America, and 3 from Africa [7]. The pooled prevalence was highest in Asia (87.99 per 100,$000 ; 95 \% \mathrm{CI}=66.83,115.86)$ and lowest in North America (36.08 per 100,000; 95\% CI $=33.50$, 38.87), which is significantly different [7]. The difference in the prevalence of MMC and spina bifida reflects different regional policies regarding folic acid fortification. Fortification is uncommon in Asia and Europe compared to North America. Live birth of children with MMC has been dropping in countries with a supporting policy for folic acid fortification [8].

Asia is the largest and highest-populated continent. The whole continent consists of 48 countries, as shown in Table 1 . The dropping prevalence of live-born MMC was also

Fetal Diagn Ther 2017;41:161-178 163 
Table 2. PubMed search result for the prevalence of myelomeningocele using keywords "myelomeningocele" and "spina bifida" for countries in Asia listed in alphabetical and chronological order

\begin{tabular}{|c|c|c|c|c|c|}
\hline Country (Area) & Year of study & $\begin{array}{l}\text { Size of study population } \\
\text { (live births), } n\end{array}$ & Cases, $n$ & $\begin{array}{l}\text { Prevalence per } \\
1,000 \text { births }\end{array}$ & First author [Ref.], year \\
\hline Australia (Southern) & $1966-1991$ & 525,130 & 398 & 0.76 & Chan [15], 1993 \\
\hline Australia (Western) & $1980-2006$ & 667,825 & 549 & $\begin{array}{l}1.54 \text { (Aboriginal) } \\
0.78 \text { (Non-Aboriginal) }\end{array}$ & Bower [14], 2009 \\
\hline Bangladesh & $2006-2007$ & 20,267 & 32 & 1.6 & Dey [18], 2010 \\
\hline China (Guizhou Province) & $1996-2004$ & 99,888 & 59 & 0.59 & Liu [38], 2007 \\
\hline China (Northern) & $2000-2014$ & 234,225 & n.a. & 1.5 (in 2014) & Liu [9], 2016 \\
\hline $\begin{array}{c}\text { China (Shanxi Province: Pinding, } \\
\text { Xiyang, Taigu, and Zezhou) }\end{array}$ & 2003 & 11,534 & 67 & 5.81 & $\operatorname{Li}[12], 2006$ \\
\hline China (Beijing) & $2003-2009$ & 61,272 & 2 & 0.03 & Li [37], 2009 \\
\hline $\begin{array}{r}\text { China (Luliang Prefecture } \\
\text { and Shanxi Province) }\end{array}$ & $2004-2005$ & 6,420 & 25 & 3.894 & Chen [35], 2009 \\
\hline China (Nationwide) & $2006-2008$ & 2,257,663 (live + stillbirths) & 4,071 & $\begin{array}{l}0.6(0.92 \text {, and } 0.31 \text { for } \\
\text { Northern and Southern } \\
\text { China, respectively) }\end{array}$ & $\operatorname{Li}[16], 2013$ \\
\hline China (Zhejiang Province) & $2007-2009$ & $\begin{array}{l}537,593 \text { singletons, } \\
14,606 \text { twins, and } \\
366 \text { triplets }\end{array}$ & $\begin{array}{l}189 \text { in singletons } \\
\text { and } 12 \text { in multiples }\end{array}$ & $\begin{array}{l}0.347 \text { in singleton and } \\
1.616 \text { in multiples }\end{array}$ & Zhang [34], 2011 \\
\hline India (Systematic review, Nationwide) & $1966-2007$ & 308,387 & 1,310 & 1.9 & Bhide [29], 2013 \\
\hline India & $1970-2013$ & 547,803 & 2,465 & 4.5 & Allagh [13], 2015 \\
\hline India (East Delhi) & $1988-1990$ & 9,220 & 24 & 2.6 & Sood [30], 1991 \\
\hline India (Shimla) & $1991-1995$ & 10,100 & 17 & 1.68 & Grover [32], 2000 \\
\hline India (Pondicherry) & $1998-2004$ & 54,738 & 170 & 3.1 & Mahadevan [31], 2005 \\
\hline India (Central) & $2005-2007$ & 9,194 & 4 & 0.41 & Taksande [36], 2010 \\
\hline India (Eastern) & $2011-2012$ & 12,896 & 18 & 1.4 & Sarkar [19], 2013 \\
\hline India (Kashmir Valley) & $2013-2015$ & 248,678 & 85 & 0.342 & Laharwal [28], 2016 \\
\hline Japan (Osaka) & $1948-1990$ & 131,996 & 17 & 0.13 & Imaizumi [40], 1991 \\
\hline Japan (Ishikawa Prefecture) & $1981-2000$ & 201,656 & 30 & 0.2 & Seto $[41], 2003$ \\
\hline Malaysia (Nationwide) & 2009 & 263,034 & 42 & 0.16 & Boo [43], 2013 \\
\hline Mongolia (Inner) & $2005-2008$ & 62,544 & 126 & 1.06 & Zhang [17], 2012 \\
\hline Nepal (Kathmandu) & 2004 & 16,601 & 8 & 0.47 & Malla [33], 2007 \\
\hline New Zealand & 1978 & n.a. & 53 & 1.02 & Borman [24], 1986 \\
\hline New Zealand & $1978-1982$ & n.a. & n.a. & 0.94 & Borman [25], 1993 \\
\hline Singapore & $1976-1987$ & 57,814 & 24 & 0.42 & Tan [26], 1989 \\
\hline Singapore & $1994-1998$ & 237,755 & 16 & 0.07 & Shi [27], 2002 \\
\hline South Korea (Nationwide) & $2005-2006$ & 883,184 & 226 & 0.26 & Kim [42], 2012 \\
\hline South Vietnam (Binh Thuan Province) & 2010 & 13,954 & 0 & 0 & Hoang [44], 2013 \\
\hline Taiwan & 2002 & 242,140 & 26 & 0.11 & Chen [39], 2009 \\
\hline Thailand (Bangkok) & $1969-1978$ & 46,276 & 12 & 0.26 & Siripoonya [20], 1980 \\
\hline Thailand (Southern) & $1988-1999$ & 27,061 & 9 & 0.33 & Dissaneevate [21], 2003 \\
\hline Thailand (Bangkok) & $1990-1999$ & 180,000 & 59 & 0.33 & Wasant [22], 2005 \\
\hline Thailand (Southern) & $2009-2012$ & 148,759 & 11 & 0.07 & Jaruratanasirikul [23], 2014 \\
\hline
\end{tabular}

observed in the recently published cohort from China [9]. This trend was attributed to a wider adoption of periconceptional supplementation of folic acid, earlier antenatal diagnosis, and termination of affected pregnancies [10]. Most of the spina bifida cases are now from the rural area [9]. Asia is more diverse than North America or Europe, since it includes some of the world's least developed as well as highly developed countries. The prevalence of NTDs in the countries in Asia varies considerably by geographical areas, with a reported prevalence between 0.2 and 58 per 1,000 births [11-13]. We have conducted a PubMed search for an actual prevalence of MMC in various parts of Asia. The keywords for the search were: (1) "spina bifida" or "myelomeningocele," and (2) "prevalence," or "epidemiology." There were 34 citations with complete information on the live births and number of spina bifida and MMC cases. Publications that did not differentiate "neural tube defect" from "myelomeningocele" or "spina bifida," and publications not accessible online were not included. The results are shown in Table 2 [9, 12-44].

Our PubMed search is certainly not equivalent to a systematic review or meta-analysis. It has several important points of heterogeneity, i.e., NTDs in multiple congenital malformations and inconsistent definitions of MMC or spina bifida used for individual publication. However, it confirms that there is a significant discrepancy in the prevalence of MMC from different geographic areas, even in the same country. According to our review, the lowest prevalence of MMC is in the southern part of Thailand, whereas certain areas of China and India have the highest prevalence. NTD is the most common congenital anomaly in India [45]. This conclusion is in 
Table 3. List of components required for prenatal repair of meningomyelocele

Program director: experienced in integrating surgical, medical, and diagnostic specialties

Medical coordinator(s)

Maternal-fetal medicine specialists

Pediatric surgeons

Neonatologists

Pediatric neurosurgeons

Genetic counselors

Social workers

Psychologists

Fetal or pediatric cardiologists

Radiologists, or sonographers, or diagnostic ultrasound specialists

Magnetic resonance imaging (MRI) specialists on ultrafast MRI sequence and neurological imaging
Developmental pediatricians

Neuropsychologists

Physical and occupational therapists

Child life specialists

Rehabilitation trainers

Insurance billing specialists

Research coordinators and staff

Internal Review Board (IRB) coordinator

Ethicists

Institutional Oversight Committee (IOC)

External Advisory Board agreement with another recent systematic review of the global prevalence of NTDs [6]. Proactive measures to find the candidate cases to keep an adequate number to maintain the skill of a fetal surgery team must focus on those regions with high disease prevalence.

\section{Appropriate Training for in utero Repair of $M M C$}

Postnatal surgical repair of MMC is a readily available procedure in North America. Orchestration of a competent multidisciplinary team through a clinical care pathway is the key factor for a successful program. When the candidate case is identified, CHOP recommends 2 days of counseling by a multidisciplinary team (details in Appendix 2). Training for intra- and postoperative management of prenatal MMC repair (details in Appendices 3 and 4) can be accomplished through a clinical attachment (observership) system. Hands-on experience is limited by licensure restriction. Subspecialty-trained professionals and supportive personnel required for an open fetal surgery program are shown in Table 3 . The components can be modified accordingly to accommodate the local restriction and practices. At the minimum, the team should have specialists with formal training and board certification in subspecialties of maternal fetal medicine, neurosurgery, pediatric surgery, pediatric or fetal cardiology, and anesthesiology. It will be advantageous to have a dedicated radiologist and a dedicated counselor in the team. The regionalization approach among Asian countries can be limited by a broad variety of training requirements and registration/licensure policies for medical professions. Technological transfer in the region can be improved by loosening these barriers and rigid implementation of a transparency policy.

A distinct advantage of in utero repair of MMC is a higher potential for wound healing and regeneration of neural fibers [46]. Currently, there are 2 major surgical approaches to access fetal spinal defect: open hysterotomy and endoscopy. Critical evaluation of each approach requires analysis of fetal benefit weighing with maternal risks. Open hysterotomy has an advantage that it implements a triple-layer repair technique, which is readily the practice standard for the neuropediatric surgeons. Alternatively, endoscopic approach is less invasive to the mother, but it is still in the initial phase. Separated studies reported a higher incidence of fetal death, intraoperative complications, and suboptimal outcomes [47-49]. Accumulation of experiences and modifications of endoscopic surgical techniques have been made, and outcome data from the endoscopic approach is catching up [50]. An important progress for endoscopic approach was the implementation of single-layer repair and biocellulose patch for defect closure, pioneered by groups in Brazil and Germany, respectively. These novel approaches allowed for a satisfactorily protection of the herniated neural tissue, and obviated the need to perform standard triple layer repair through an endoscopy [51-53]. The most recent published experiences from the CECAM trial demonstrated a significant improvement in outcomes according to the growing experiences [54]. The risk-benefit analyses for the fetus and the mother between open and endoscopic prenatal repair of MMC are summarized in Table 4 [48, $55,56]$. Data related to long-term functional outcomes (>12 months) from the endoscopic approach are still underway. With tissue engineering-based approach (i.e., injectable scaffolds) on the horizon, the current operative approaches using multiple trocars may soon be replaced $[57,58]$. 
Table 4. Recent systematic reviews and meta-analyses of risks and benefits to the fetus and the mother related to open hysterotomy and endoscopic approaches for prenatal repair of myelomeningocele

\begin{tabular}{|c|c|c|c|}
\hline First author [Ref.], year & Cases, $n$ & $\begin{array}{l}\text { Fetal risks-benefits } \\
\text { (open vs. endoscopic) }\end{array}$ & $\begin{array}{l}\text { Maternal risks-benefits } \\
\text { (open vs. endoscopic) }\end{array}$ \\
\hline $\begin{array}{l}\text { Joyeux [56], } 2016 \\
\text { (data presented as } \\
\text { percentage and } p \\
\text { values) }\end{array}$ & $\begin{array}{l}\text { Open: } 78 \text { (exclusively from } \\
\text { the Management of } \\
\text { Myelomeningocele Study } \\
\text { [MOMS]) } \\
\text { Endoscopic: } 51 \text { (operative, } \\
\text { maternal, and fetal } \\
\text { outcomes) + } 71 \text { (infant } \\
\text { mortality and neurological } \\
\text { outcomes at } 12 \text { months) }\end{array}$ & $\begin{array}{l}\text { Perinatal mortality: } 2.6 \text { vs. } 7.8 \%(p=0.212) \\
\text { Ventriculoperitoneal shunt rate at } 12 \text { months: } 40 \text { vs. } 45 \% \\
(p=0.619) \\
\text { Preterm premature rupture of the membranes: } 84 \text { vs. } 46 \% \\
(p<0.001) \\
\text { Gestational age at birth: } 34.1 \text { vs. } 28 \text { weeks }(p=0.03) \\
\text { Postnatal reoperation rate: } 2.56 \text { vs. } 28 \%(p<0.001)\end{array}$ & $\begin{array}{l}\text { Operation time: } 105 \text { vs. } \\
223 \text { min }(p<0.001) \\
\text { Uterine thinning or } \\
\text { dehiscence: } 64 \text { vs. } 0 \% \\
(p<0.001)\end{array}$ \\
\hline $\begin{array}{l}\text { Araujo Junior [55], } \\
2016 \\
\text { (data presented as } \\
\text { percentage [95\% CI] } \\
\text { and authors' } \\
\text { interpretation) }\end{array}$ & $\begin{array}{l}\text { Open: } 827 \\
\text { Endoscopic: } 81\end{array}$ & $\begin{array}{l}\text { Ventriculoperitoneal shunt rate at } 12 \text { months: } 40 \%(29-51 \%) \text { vs. } \\
45 \%(34-56 \%) \text { (no difference) } \\
\text { Reversal of hindbrain herniation: } 34 \%(28-52 \%) \text { vs. } 86 \% \\
(49-97 \%)\left(\text { none }^{a}\right) \\
\text { Lower extremity function: } 47 \%(30-64 \%) \text { vs. } 86 \%(49-97 \%) \\
\text { (none }^{\text {a })} \\
\text { Bladder dysfunction: } 72 \%(53-88 \%) \text { vs. } 29 \%(8-64 \%)\left(\text { none }^{a}\right)\end{array}$ & Not available \\
\hline $\begin{array}{l}\text { Araujo Junior [48], } \\
2016 \\
\text { (data presented as } \\
\text { percentage [95\% CI] } \\
\text { and authors' } \\
\text { interpretation) }\end{array}$ & $\begin{array}{l}\text { Open: } 456 \\
\text { Endoscopic: } 84 \text { (with } 4 \text { cases } \\
\text { of technical failure) } \\
\text { Combined open and } \\
\text { endoscopic: } 1\end{array}$ & $\begin{array}{l}\text { Preterm delivery <34 weeks: } 45 \%(38-53 \%) \text { vs. } 80 \%(41-100 \%) \\
\text { (open is possibly better) } \\
\text { Oligohydramnios: } 14 \%(7-24 \%) \text { vs. } 39 \%(9-75 \%) \text { (open is } \\
\text { possibly better) } \\
\text { Preterm premature rupture of the membranes: } 38 \%(26-50 \%) \\
\text { vs. } 67 \%(12-100 \%) \text { (open is possibly better) } \\
\text { Chorioamnionitis: } 3 \%(2-6 \%) \text { vs. } 6 \%(2-13 \%) \text { (no difference) } \\
\text { Perinatal death: } 5 \%(3-8 \%) \text { vs. } 14 \%(1-38 \%) \text { (open is possibly } \\
\text { better) }\end{array}$ & $\begin{array}{l}\text { Uterine dehiscence: } 26 \% \\
(12-42 \%) \text { vs. } 1 \%(0-4 \%) \\
\text { (endoscopic is better) } \\
\text { Placental abruption: } 3 \% \\
(0-8 \%) \text { vs. } 2 \%(0-9 \%) \\
\text { (no difference) }\end{array}$ \\
\hline
\end{tabular}

${ }^{a}$ The estimate in the endoscopic surgery is still very imprecise to allow meaningful conclusions.

\section{Established Fetal Therapy Center}

Definition of Fetal Therapy Center

Due to the complexity of the disease and its therapeutic procedure, it was agreed that in utero repair of MMC should be performed only in an established FTC. The definition of an FTC is a facility dedicated to a multidisciplinary, integrated cross-institutional program for the prenatal diagnosis, antenatal management, delivery, and in utero treatment of fetal disorders. In addition, an FTC must be able to manage newborn babies in critical condition due to major congenital malformations and/or genetic disease. It is desirable that an FTC should have a seamless line of patient care including accurate prenatal diagnosis, nondirective counseling, financial arrangement, in utero intervention, and a maternity and delivery service. It is also recommended that FTC also provide services in postnatal surgical intervention and a childhood rehabilitation program. It requires people from a broad array of medical and social specialties to team up and work in a harmonious fashion to achieve this goal.

\section{Counseling}

Counseling the expectant mother and her family is a real challenge. Although there may be difficulty in communicating potential risks and benefits of the offered therapy, patients are likely to minimize the recognized personal and fetal risks of in utero intervention in a desperate bid to seek the best possible outcome. The enthusiasm of medical fraternity has to be tempered with caution. The patient needs to be made aware that for various reasons and circumstances, outcomes seen in already established centers may not be reproducible in the Asian context, and there will surely be a learning curve. The family and friends can put additional unrealistic pressure on the woman. It requires an approach from various aspects (details in Table 3) for the expectant mother to make an informed decision without coercion or time constraint. Strong institutional support and commitment are crucial for facilitating this model of nondirective counseling based on participation. (The components required for critical care can be divided into the surgical team and the delivery and postoperative team.)
166

Fetal Diagn Ther 2017;41:161-178 DOI: $10.1159 / 000452218$
Wataganara et al. 


\section{Personnel}

The personnel actively involved in the area of open fetal MMC repair can be categorized into 3 groups. (1) The surgical team has to be available at all times. The minimum requirement of a specialist team that needs to be on call includes a pediatric surgeon, maternal-fetal medicine specialist, fetal or pediatric cardiologist, subspecialty pediatric surgeon, obstetrical or fetal anesthesiologist, dedicated operating room team of scrub nurses (at least 2), circulating nurses (at least 2), and support staff (at least 1). All the "core members" are committed to maintain their expertise by adequate case volume and regular simulation exercises. (2) The delivery team and (3) the postoperative team consist of a maternal-fetal medicine specialist and obstetrician who have training and experience in clinical care of women during their recovery from open fetal surgery. It requires a combination of knowledge, skill, and experience to recognize and manage complications of open fetal surgery in a timely fashion. Immediate complications include postoperative pulmonary edema, fetal membrane separation, premature rupture of the membranes, incessant preterm labor that require aggressive tocolysis, rupture or dehiscence of uterine hysterotomy, and massive bleeding from morbidly adherent placenta. On this specialized Labor and Delivery floor, there must be a dedicated cohort of nurses who have been trained to recognize and provide initial resuscitation, for both the mother and the high-risk newborn baby, from post-open fetal surgery complications. There must be a dedicated cohort of neonatal resuscitation team and in-house obstetrical anesthesiologist who are familiar with anomaly-specific protocol for individual congenital anomalies.

If the fetus cannot be saved, the woman and her family should be guided to bereavement programs, including palliative care and religion-specific support services. Additional support from psychosocial workers, maternal advocates, as well as pediatric genetic counseling is always helpful. Postmortem physical examination of the fetus as well as a detailed autopsy to delineate associated anomalies should be routinely offered to the family.

\section{Developing and Maintaining Skills for Open Fetal} Surgery

As part of mandatory quality assurance, FTCs that decide to offer open fetal surgery must develop a dedicated fetal surgical team with established expertise in their specialties. The team members are required to be available for emergencies at any time. New FTCs should seek training and guidance from experienced individuals or FTCs that are directly involved in the established open fetal sur-

Prenatal Myelomeningocele Surgery in Asia gery program with mentorship. There has been an ongoing controversy as to what level of experience is necessary to earn the designation "qualified" FTC. Direct experience with 5-20 cases of open fetal surgery under supervision or distant monitoring is acceptable according to some expert discussants.

Once the system is established, maintenance of the necessary case volume and expertise is the next real challenge. There is an increasing competition to attract patients among FTCs. Experts from CHOP (A.W.F. and M.P.J.) proposed a minimum of 5-10 cases annually as a sufficient referral volume to maintain team skills and experience. However, this goal may not be necessarily achieved, because not all the referred cases will meet the inclusion criteria for the surgery. Europe and Asia had more high-volume centers, whereas South America, the Middle East, and Australia had mainly low-volume centers [59]. A recent post-MOMS publication has shown that only $29 \%$ of referrals are actually eligible [60]. It has not been universally agreed if ex utero intrapartum treatment deliveries count toward this minimum annual volume requirement. FTCs must have Institutional and Outside Oversight Committees to monitor their outcomes on an at least annual basis. This unbiased monitoring is to assure quality of care that meets national standards. If problems are identified, or the practices are not meeting standards, FTCs would (1) need to require additional training, (2) enforce established protocols, or (3) consider terminating the program if safety and care benchmarks cannot be met. Finally, whether an FTC can maintain minimum procedures per annum or not, regular teambased simulation exercises are important so that the team members will remain competent in their specific assignment.

Expansion of Existing Fetal Therapy Programs:

Quality Assurance and Maintenance of the Necessary Case Volume and Expertise

MOMS included the 3 most experienced open fetal surgery programs in the world: the Children's Hospital of Philadelphia, Vanderbilt University, and the University of California, San Francisco, in order to concentrate surgical expertise, minimize maternal and fetal morbidity, and optimize infant outcomes. Therefore, it is not unexpected that numerous questions and concerns arise after the trial completion. There are issues of (1) generalizability of the results from MOMS to other FTCs with less experience, (2) appropriate measures for new FTCs to develop and maintain similar levels of expertise, (3) establishment of national and international care standards

Fetal Diagn Ther 2017;41:161-178 167 
and benchmarks for in utero repair of MMC, and (4) development of mechanisms to monitor the outcomes. While there are appropriate protocols for the newly established FTCs to properly offer open fetal surgery for MMC, some FTCs have started to offer this novel treatment without unbiased evaluation of inclusion and exclusion criteria as well as operative techniques. A significant variation in practice patterns for offering and performing the open surgery were observed, according to a recent publication by the North American Fetal Therapy Network (NAFTNet) [61].

NAFTNet has suggested an approach of regionalization of programs to increase access to therapy, and to establish recognized "centers of excellence." Experienced FTCs can help develop the open fetal surgery program in new FTCs by offering mentoring or training. Minimum resources and necessary clinical expertise criteria should be established to achieve the "experienced center" status. It should be mandatory to have oversight programs for FTCs to monitor outcomes and maintenance of minimal experience to retain the "center of excellence" status.

FTCs with longest experience may attain the "Research and Development Center" status. In addition to ongoing refinement and innovation, FTCs at this level are required to have established programs to gather standardized long-term outcome data. This information (1) will improve an understanding of the composite impact of fetal intervention, (2) can be used for prenatal counseling of candidate patients, and (3) can validate the actual benefits of such interventions. When there are enough number and adequate regional coverage of FTCs offering open fetal surgery for MMC with the same standard and quality, a central national or international registry of cases should be established. Pooling of standardized data from multicenter or multinational collaboration will provide large-scale data to predict perinatal, as well as long-term neurodevelopmental and functional outcomes of fetuses that undergo in utero repair of MMC. This collaboration will allow for sharing of high-quality data among experienced FTCs, which may lead to (1) proposal of future research projects to refine prenatal care, (2) introduction of surgical innovation, or (3) optimization of the management based on scientific validation in controlled clinical trials or studies.

\section{Follow-Up Data: Short and Long Term}

Systematic collection of data on predetermined outcome measures, processing and sharing the results would be essential for benchmarking and quality assurance of that FTC and to confirm a successful generalization of
MOMS results. The parameters collected for this evaluation were listed in the original publication of MOMS [1]. It is likely that an FTC that begins to offer open fetal MMC repair will not have a sufficient number of patients to make sense of all the parameters collected by the MOMS research team. Selective collection of only key parameters that represent the major outcomes may be enough in the newly found FTCs. These key parameters are summarized, and a simplified Case Record Form (CRF) is provided in Table 5. Extended follow-up after 30 months' corrected gestational age needs to be established at that FTC or another FTC that has the necessary specialty services as this is essential for long-term outcomes monitoring and reporting. It may include, but not be limited to the conditions and treatments of the following systems: neurodevelopment, bowel-bladder function and continence, and socialization [62]. Ideally, the follow-up should continue well into adolescent and adult years.

\section{Regional Issues Related to Adoption of the Procedure}

Long-term risks to the mother, particularly for the future pregnancies, are not negligible in certain parts of Asia where access to standard prenatal care is still limited. The MOMS Trial was conducted in the USA, a developed nation, where an overall rate of Cesarean delivery is approximately 30\% [63]. Maternal morbidities reported from the MOMS Trial may not be extrapolated to other places in the world. A combination of low Cesarean section rate and limited access to prenatal care in certain parts of Asia can make subsequent pregnancies lifethreatening to mothers who underwent open hysterotomy repair of fetal MMC. Because of this high long-term risk to the mother, the promise of minimally invasive repair has to be considered. Fetal benefits from the endoscopic approach are catching up, and rapidly paralleling with those of open repair. The benefits and risks to the fetus and the mother will have to be reassessed from the most updated outcome data in the literature. The translation of these outcomes in the region will have to be validated through regular communication among the fetal medicine experts. In the future, a broader circle of specialists will be involved to contribute their inputs to tailor this preliminary strategy for specific areas of Asia.

Late diagnosis is not uncommon in countries with low medical resources. First-trimester screening for Down syndrome is not universally offered in many parts of Asia. For example, it was offered $90 \%$ of the time in Hong Kong, according to the statistics from a recent survey of 331 specialist obstetricians (32\% response rate) [64]. Hong Kong is one of the most developed places in Asia;
168

Fetal Diagn Ther 2017;41:161-178 DOI: $10.1159 / 000452218$
Wataganara et al. 
Table 5. An example of the Case Record Form to collect key parameters reflecting outcomes of prenatal repair of myelomeningocele in comparison with the results from the MOMS Trial (modified from Adzick et al. [1])

\begin{tabular}{|c|c|c|c|}
\hline Category & Parameters & Results & Details \\
\hline \multicolumn{4}{|l|}{ (A) Main outcomes } \\
\hline \multirow{2}{*}{$\begin{array}{l}\text { Primary } \\
\text { (1 of the following) }\end{array}$} & \multirow{2}{*}{\multicolumn{3}{|c|}{$\begin{array}{l}\text { Death by } 1 \text { year of life } \\
\text { Need for decompressive ventricular shunting by } 1 \text { year of life } \\
\text { Termination of pregnancy }\end{array}$}} \\
\hline & & & \\
\hline \multirow[t]{2}{*}{ Composite } & $\begin{array}{l}\text { Bayley Scales of Infant Development; evaluated at } 30 \text { months } \\
\text { corrected age }\end{array}$ & \multirow{2}{*}{\multicolumn{2}{|c|}{$\begin{array}{l}\text { Mental Development Index (MDI) } \\
\text { Death }(\text { score }=0)\end{array}$}} \\
\hline & $\begin{array}{l}\text { Distal somatosensory function and motor sensory assessment } \\
\text { of level of lesion }\end{array}$ & & \\
\hline \multicolumn{4}{|l|}{ (B) Morbidity } \\
\hline \multirow[t]{8}{*}{ Maternal/paternal } & Gestational age at delivery & & \\
\hline & Maternal death & & \\
\hline & Maternal and paternal psychosocial status at delivery, 12 and & & \\
\hline & 30 months after delivery & & \\
\hline & Oligohydramnios & & \\
\hline & Uterine rupture & & \\
\hline & Maternal reproductive functioning at 30 months after delivery & & \\
\hline & Pulmonary edema & & \\
\hline Neonatal & $\begin{array}{l}\text { (1) Neonatal death or stillbirth, or (2) bronchopulmonary } \\
\text { dysplasia, or (3) pulmonary interstitial emphysema, or (4) } \\
\text { retinopathy of prematurity, or (5) pulmonary hypoplasia, or } \\
\text { (6) necrotizing enterocolitis, or (7) patent ductus venosus, or } \\
\text { (8) seizures, or (9) intraventricular hemorrhage, or (10) } \\
\text { periventricular leukomalacia, or (11) sepsis }\end{array}$ & & \\
\hline \multirow[t]{11}{*}{ Infant } & Radiographic appearance of the Chiari II malformation ${ }^{b}$ & & \\
\hline & Time to first shunt placement & & \\
\hline & Number of shunts and revisions & & \\
\hline & Number of surgical procedures for related conditions ${ }^{c}$ by & & \\
\hline & 30 months' corrected age & & \\
\hline & $\begin{array}{l}\text { Locomotion at } 30 \text { months' corrected age: (1) independent } \\
\text { ambulation, or (2) braces, or ( } 3 \text { ) wheelchair bound }\end{array}$ & & \\
\hline & Brain stem function & & \\
\hline & & \multirow{4}{*}{\multicolumn{2}{|c|}{$\begin{array}{l}\text { Swallowing profile } \\
\text { BSAER tests }\end{array}$}} \\
\hline & Motor scales (Bayley Scales of Infant Development) & & \\
\hline & Degree of functional impairment & & \\
\hline & Number of days of total hospitalization through 30 months & & \\
\hline
\end{tabular}

(C) Extended follow-up (optional)

\footnotetext{
${ }^{a}$ Objective criteria for shunting (at least 1 of the following): (A) progressive hydrocephalus, at least 2 of the following: (1) an increase in the greatest occipital-frontal circumference adjusted for gestational age defined as crossing percentiles, (2) a bulging fontanelle OR split sutures OR sunset sign, (3) increasing hydrocephalus on consecutive imaging studies (increase in ratio of biventricular diameter to biparietal diameter), (4) head circumference over 95th percentile of the gestational age; (B) presence of marked syringomyelia (syrinx with expansion of spinal cord) with ventriculomegaly (undefined); (C) ventriculomegaly (undefined) and symptoms of Chiari malformation (stridor, swallowing difficulties, apnea, bradycardia); (D) persistent cerebral spinal leakage from the myelomeningocele wound or bulging at the repair site. ${ }^{\mathrm{b}}$ Radiographic appearance of the Chiari II malformation (cerebellar herniation below the foramen magnum): (A) location of the cerebellum in relation to the foramen magnum; (B) presence of cervicomedullary kink; (C) size and location of the fourth ventricle; and (D) presence of hydrocephalus. ${ }^{\mathrm{c}}$ Related conditions (at least 1 of the following): (A) tethered cord; (B) hydrosyringomyelia; (C) feeding problems; (D) gastrointestinal reflux; (E) urinary or fecal control; (F) orthopedic deformities (i.e., kyphoscoliosis).
}

therefore, the uptake rate for first-trimester screening is expected to be lower than this in most parts of Asia [64]. In addition, even when offered, Asian women are more likely to refuse to have the screening test [65]. Without prenatal screening early on in pregnancy, it is conceivable that a bigger proportion of fetal MMCs are diagnosed when the gestational age is too advanced for legal termination. That leaves either expectant management with planned birthing or in utero intervention as an option. Unbiased, nondirective counseling is particularly important for women from a disadvantaged social background, to ensure that the choice they make is well informed [66]. 


\section{Discussion and Conclusions}

A solid consensus for an appropriate adoption of open fetal repair for MMC cannot be organized until all the stakeholders in the region can contribute their inputs. However, preliminary essential steps for further development of fetal therapy in the region have been suggested, and endorsed by the assembly, which represented only parts, but not all, of Asian countries. The list of suggestions is named the "Singapore Consensus" for the purpose of future reference. The key messages are the following:

(1) It is important to set a goal. Short- and long-term accomplishments should be drafted with a realistic timeline. The first goal is to determine the true area-specific prevalence of NTDs, which is still lacking in some regions. The FTC in each region should have a commitment to identify and validate the actual magnitude of, not only MMC, but other prenatally detected conditions that have serious consequences. Fetal diseases that impact in utero development resulting in significant challenges to maintain optimal quality of life after birth deserve this surveillance.

(2) From the currently available epidemiological data, it is conceivable that the prevalence of MMC in Asia is comparatively higher than that in the USA and Europe. However, the total prevalence, compared to other fetal conditions amendable to in utero treatments, is low. The prevalence of live-born babies with MMC is expected to fall in the future due to the broader adoption of periconceptional folic acid fortification. With this prevalence, FTCs who are offering open fetal surgery for MMC must maintain the skill of their team by following these steps:

(2.1) Providing accurate diagnosis at early gestational age by an experienced team, with adequate imaging technologies. Diagnostic and therapeutic concepts need to be standardized among regional FTCs who wish to participate in the network.

(2.2) Offering appropriate cytogenetic and molecular genetic testing.

(2.3) Counseling the patient and her family in an unbiased manner.

(2.4) Referring patients and their families to FTCs in the region that are experienced and have established postnatal care programs for that specific fetal disease. This approach is to ensure an adequate number of cases per annum to maintain their skills and for obtaining the best possible postnatal outcomes. Networking with the areas of high MMC prevalence, i.e., China, can provide bilateral benefit in this regard.
(2.5) Standardization of follow-up protocols, including neonatal survival and morbidity, composite outcomes in the childhood period, and other disease-specific outcomes. This approach can help generate meaningful data that can be used for counseling, or as a benchmark to improve the quality of FTC.

(2.6) Adequate training and regular practice for interventionists and their support staff. The level of training can be varied, but it is important that everyone in the team is very specific, and very motivated, for their parts. Initially, clinical attachment or observership in experienced FTCs in the USA can be arranged. Mentors can help young FTCs that are considerably inexperienced with the procedure to set up the program, with their specific circumstances and both advantages and limitations taken into consideration.

(3) The newly adopted complex procedures need to be accompanied by mentorship until surgical skill satisfactions are met by both parties. Then, remote proctorship may be utilized to assure maintenance of proficiency in the new procedure. The number of cases for each step has not been established, but it may vary from one center to another based on previous fetal therapy experience.

(4) FTCs must be committed to report the neonatal outcomes and procedure-related morbidities in a frank and honest manner. Long-term outcomes in the childhood period are essential after in utero repair of MMC $[67,68]$.

(5) More experienced FTCs are committed to transfer their knowledge, when requested, to the other less experienced FTCs. Knowledge sharing can be through lecture, simulation workshop, clinical observership, research fellowship, or even clinical fellowship training.

\section{Acknowledgements}

The content of this paper was partially derived from an invited round table discussion of multidisciplinary specialists from established fetal care centers in Thailand, Hong Kong, India, and Singapore. We would like to thank Ginny Chen and Kun Pei Huang for their time and effort to put together the assembly. The meeting was hosted by the Department of Obstetrics and Gynecology, National University Hospital Systems, Singapore, on April 18, 2016, during the 2nd Asia Pacific Conference of Fetal Therapy (APCFT). It was part of an initiative for collaboration to improve quality of fetal care in the region.
Wataganara et al. 


\section{Appendix 1}

Questionnaire distributed to the discussants of the round table discussion.

Part A: basic problems and resources

1. Magnitude of neonatal and childhood problems for the following conditions: case load per annum and its burden on individual and social scale. This will be remarkably varied from one Asian country to another

1.1. Myelomeningocele

1.2. Congenital pulmonary airway malformation

1.3. Sacrococcygeal teratoma

1.4. Miscellaneous

2. Available resources at each fetal care center

2.1. Number and quality of fully trained and experienced pediatric surgeon, neurosurgeon, and ENT specialist

2.2. NICU level and availability

2.3. Funding of the fetal care center: public or private

2.4. Healthcare system: government-subsidized or private insurance

Part B: developing the essentials for open fetal surgery

3. Medical personnel (MDs and non-MDs): Who requires the training and at what levels?

3.1. Lectures (non-MDs)

3.2. Model or simulator training (fellows)

3.3. Animal model (research fellow)

3.4. Visiting fellowship, research fellowship (faculty member, but limited hands on practice)

4. Purpose-designed equipment

4.1. What should be in the start-up set

4.2. Maintenance

5. Seamless work flow for timely action from multidisciplinary team

5.1. Dedicated medical coordinator and leader

6. Monitor, audit, critical review, and then publish

\section{Appendix 2}

Standardized protocol for prenatal evaluation and management of a fetus with myelomeningocele (MMC) [1].

(A) Prenatal evaluation of a fetus with MMC

Day 1

1. Fetal echocardiography, diagnostic ultrasound, and ultrafast MR imaging

2. Confirmed normal karyotype a, elevated levels of amniotic fluid $\alpha$-fetoprotein, and presence of acetylcholinesterase to confirm a non-skin covered defect and absence of significant associated anomalies that could alter the benefits of fetal intervention

3. Maternal genetic, medical, and obstetrical screening for risk factors that may contraindicate fetal surgery

4. Non-directive counseling which includes (1) discussion of the natural history of MMC in fetal and childhood period, (2) discussion of all possible management options including pregnancy termination and palliative care, and (3) full disclosure of all possible risks and potential benefits of each management option according to the published data

5. If the patient is interested in fetal intervention, nondirective counseling "must" include hard data on (1) reported maternal and fetal complications following surgery, (2) infant survival and neonatal complications, (3) long-term developmental and cognitive outcomes, and (4) full disclosure of maternal risks for the present and future pregnancies as well as (5) prophylactic measure to limit these risks, such as pregnancy interval

Day 2

1. Maternal psychosocial evaluation (maternal advocate)

2. Consultation and discussion with fetal or obstetric anesthesiologist

3. Consultation and discussion with maternal fetal medicine specialist and fetal surgeon

4. Consultation and discussion with neonatologist (issues of iatrogenic prematurity)

5. Social work evaluation

6. Consultation and discussion on postoperative care issues

7. Meeting with billing or insurance specialist

8. Overnight "reflective period" of decision making

Day 3 if family confirms their wish to go forward with fetal surgery

1. Preoperative laboratory studies, chest X-ray, EKG

2. Multidisciplinary team meeting 


\section{Appendix 3}

Standardized protocol for prenatal evaluation and management of a fetus with myelomeningocele (MMC) [1].

(B) Intraoperative management of open surgical repair of fetal MMC

1. Patient preparation

a. Preoperative prophylaxis: cefazolin (1-g IV bolus) and indomethacin (50 $\mathrm{mg}$ per rectum or oral)

b. Combination of general anesthesia

c. Preoperative placement and testing of epidural catheter to be dosed at completion of the surgery for postoperative pain management

2. Entry peritoneal cavity

a. Transverse laparotomy incision (or vertical skin incision in obese women)

b. Confirm fetal position with ultrasound and version to vertex before exteriorizing uterus if needed and creation of the hysterotomy

c. Exposure and possible exteriorize the gravid uterus for anterior placenta

3. Choosing hysterotomy location

a. Location for hysterotomy incision is chosen in the placenta-free area under ultrasound guidance. If it is anterior placenta, hysterotomy incision can be either at the fundus or on the posterior wall. In the case of a posterior placenta, the amniotic sac can be entered from the anterior wall

b. The fetus is manually positioned such that the MMC sac is adequately exposed at the hysterotomy

4. Initial uterine access and extension of incision

a. Place 2 monofilament traction sutures through full thickness of uterine wall

b. The first entry is by sharp incision between these traction sutures

c. It is followed by uterine stapling device loaded with absorbable polyglycolic acid staples (Covidien Auto Suture, Norwalk, CT, USA)

d. Re-check, with manual palpation and ultrasound, that there is no fetal part in between the blade

e. Then use the stapler to create a 6- to 8-cm full thickness incision large enough to expose the MMC sac

5. Repair of MMC

a. Fetal analgesia and immobilization by intramuscular injection with a "cocktail" mixture of fentanyl $(20 \mu \mathrm{g} / \mathrm{kg})$ and vecuronium $(0.2 \mathrm{mg} / \mathrm{kg})$

b. Fetal cardiac function: continuous echocardiography monitoring by an individual not involved in the actual prenatal surgery

c. The myelomeningocele is closed in a standardized neurosurgical manner under magnification

d. The neural placode is sharply dissected from surrounding tissue and allowed to drop into the spinal canal

e. The dura is then identified, reflected over the placode and then closed using a fine running suture. If there was insufficient dura for closure, Duragen (Integra Life Sciences Corporation, Plainsboro, NJ, USA) was substituted

f. An alternate technique is to raise myofascial flaps that include the inner dural layer and reflected over the placode and closed using fine running suture

g. If it was not possible to obtain skin closure, Alloderm (Life Cell, Branchburg, NJ, USA) is used. Finally, the skin is mobilized and closed using a fine running monofilament suture

6. Closing of uterine incision and abdominal wall

a. The uterus is closed in two layers. The first layer incorporates the absorbable staples and uterine membranes

b. As the last stitches of this layer are placed, warmed Ringer's lactate, mixed with $500 \mathrm{mg}$ of nafcillin or vancomycin, is added to the uterus until the amniotic fluid index is normal

c. A second previously placed imbricating layer of suture is tied. The omentum is mobilized and sutured to cover the hysterotomy to provide protection and blood supply to promote healing. The abdominal fascial layer, subcutaneous space, and dermis are closed in a routine fashion 


\section{Appendix 4}

Standardized protocol for prenatal evaluation and management of a fetus with myelomeningocele (MMC) [1].

(C) Postoperative management of open surgical repair of fetal MMC

Postoperative day 0 (immediately after surgery)

1. Intravenous (IV) fluids

a. Total IV fluid is restricted to $80 \mathrm{ml}$ per hour

b. Fluid restriction is necessary because of the risk of pulmonary edema, especially when magnesium sulfate is concurrently administered

2. Magnesium sulfate

a. Patient receives $6 \mathrm{~g}$ of magnesium sulfate IV load intraoperatively at the end of the first hysterotomy layer closure

b. When she arrives in the recovery room, IV magnesium sulfate rate is generally run at $4 \mathrm{~g}$ per hour for 1 to $3 \mathrm{~h}$

c. IV infusion is then generally decreased to $3 \mathrm{~g}$ per hour for the next 4 to $6 \mathrm{~h}$, and then adjusted based on uterine activity (palpable contractions, not just contractions on tocodynamometer) until reaching $2 \mathrm{~g}$ per hour

d. Monitor serum magnesium at 6 and $12 \mathrm{~h}$ postoperatively, or if patient shows signs of magnesium toxicity. Target serum magnesium levels should be between 6.0 and $7.5 \mathrm{mg} / \mathrm{dL}$

e. Magnesium must be discontinued after a total infusion of $24 \mathrm{~h}$

3. Important monitoring

a. Pulse oximetry: for signs of pulmonary edema

b. Urine output: magnesium levels elevate and may reach toxic levels, as urine output falls

c. Signs of magnesium toxicity: slurred speech, visual changes (blurred or double vision), respiratory depression, hypoxia, absent reflexes, cardiac arrhythmia

4. Indomethacin

a. Preoperative period: indomethacin $50 \mathrm{mg}$ is administered orally

b. Postoperative period: indomethacin $50 \mathrm{mg}$ is administered per rectum every $6 \mathrm{~h}$ for 3 additional dosages (total of 4 administrations in $24 \mathrm{~h}$ )

5. Antibiotics

a. Preoperative period: cefazolin 1-g bolus is administered intravenously, or clindamycin 900-mg bolus (in penicillin-allergic cases) is administered intravenously

b. Postoperative period: cefazolin $1 \mathrm{~g}$ is administered IV piggy bag (IVPB) every $8 \mathrm{~h}$ for a total of 4 doses in $24 \mathrm{~h}$, or clindamycin $900 \mathrm{mg}$ (in penicillin-allergic cases) is administered IVPB every $8 \mathrm{~h}$ for a total of 4 doses in $24 \mathrm{~h}$

6. Pain management

a. Epidural: patient-controlled epidural analgesia (PCEA) placed preoperatively, but not started until the completion of the surgical procedure

7. Drains

a. Foley catheter to dependent drainage

8. Surveillance

a. Uterine irritability or contractions: continuous tocodynamometer measurement

b. Fetal heart rate: checks every $4 \mathrm{~h}$

c Fetal adaptation: postoperative fetal echocardiogram

9. Maternal activity

a. Strict bed rest

b. Bilateral lower leg compression boots

Key Points for Postoperative Day 0 (immediately after surgery)

Fluid restriction

Monitor $\mathrm{O}_{2}$ saturations with pulse oximeter

Monitor urine output

Sequential decrease in magnesium sulfate infusion in the postoperative period

Monitor serum magnesium sulfate levels at 6 and $12 \mathrm{~h}$ postoperatively

Prenatal Myelomeningocele Surgery in

Asia
Fetal Diagn Ther 2017;41:161-178

DOI: $10.1159 / 000452218$ 
Postoperative Day 1 (immediately after surgery)

1. Intravenous (IV) fluids

a. Total IV fluid is restricted to $100 \mathrm{ml}$ per hour

b. Fluid restriction is necessary because of the risk of pulmonary edema in first 48 h postoperatively

2. Magnesium sulfate

a. Magnesium must be discontinued after a total infusion of $24 \mathrm{~h}$, unless there are persistent palpable contractions

3. Nifedipine

a. Nifedipine is started $60 \mathrm{~min}$ after the magnesium sulfate has been discontinued

b. It is important to wait because cardiovascular collapse has been recorded when magnesium sulfate and nifedipine are used in combination

c. Nifedipine is started at $20 \mathrm{mg}$ every $6 \mathrm{~h}$, or $10 \mathrm{mg}$ every $6 \mathrm{~h}$ if maternal systolic blood pressure is less than $95 \mathrm{~mm} \mathrm{Hg}$

d. Nifedipine dose can be increased to every $4 \mathrm{~h}$ if palpable contractions are documented on every 6-h dosing

4. Indomethacin

a. After completing the 4 doses of $50 \mathrm{mg}$ indomethacin, switch to oral indomethacin $25 \mathrm{mg}$ every $6 \mathrm{~h}$ for a total of 4 doses in $24 \mathrm{~h}$ during postoperative day 1

5. Antibiotics

a. Cefazolin or clindamycin is discontinued after completing the 4 postoperative dosages on postoperative day 0

6. Pain management

a. Epidural: patient controlled epidural analgesia (PCEA)

7. Drains

a. Foley catheter to dependent drainage

8. Surveillance

a. Uterine irritability or contractions: continuous tocodynamometer measurement

b. Fetal heart rate: checks every $4 \mathrm{~h}$

c. Fetal adaptation: postoperative fetal echocardiogram and ultrasound

9. Diet

a. Afternoon: ice chips can be offered based on degree of nausea

b. Evening: clear liquids can be offered if ice chips were well tolerated through the afternoon

c. Then: oral intake can be increased ad lib

10. Maternal activity

a. Strict bed rest

b. Bilateral lower leg compression boots

Key Points for Postoperative Day 1

Magnesium sulfate discontinued after a total of $24 \mathrm{~h}$

Nifedipine starts no sooner than $60 \mathrm{~min}$ after the magnesium is discontinued

Indomethacin doses change from $50 \mathrm{mg}$ per rectum to $25 \mathrm{mg}$ orally every $6 \mathrm{~h}$

Postoperative Day 2

1. Intravenous (IV) fluids

a. Heparin-locked IV access if patient tolerates clear liquids

2. Nifedipine

a. Nifedipine dose continues at $20 \mathrm{mg}$ every $6 \mathrm{~h}$ or $10 \mathrm{mg}$ every $6 \mathrm{~h}$ if maternal systolic blood pressure is lower than $95 \mathrm{~mm} \mathrm{Hg}$

b. Nifedipine dose can be increased to every $4 \mathrm{~h}$ if palpable contractions are documented on every 6 -h dosing

3. Indomethacin

a. Indomethacin is discontinued after completing the 4 doses of $25 \mathrm{mg}$ 
4. Pain management

a. Discontinue epidural

b. Oral pain medications

7. Drains

a. Discontinue Foley catheter is once the epidural catheter is removed

8. Surveillance

a. Uterine irritability or contractions: continuous tocodynamometer

b. Fetal heart rate: checks every shift

c. Fetal adaptation and surgical complications: postoperative ultrasound evaluation

9. Diet

a. Advanced or regular diet: if clear liquids are tolerated

b. Consider bowel function (Colace): as they are very prone to constipation secondary to inactivity and pain medications

10. Maternal activity

a. Bilateral lower leg compression boots should be continued when in bed

b. Progressive mobilization after epidural has been discontinued and Foley catheter removed

b.1. Sitting up in bed for several hours to start with

b.2. Sitting on the edge of bed and dangling legs

b.3. Walking to the bathroom with assistance

Key Points for Postoperative Day 2

Dizziness and palpitations are common during the first 1-2 weeks of nifedipine treatment

As such, one needs to be aware of this when initiating mobilization

Oral pain medications should be started

Colace (100 mg twice daily) should be started

Discharge planning for housing and wheelchair

Postoperative Day 3

1. Intravenous (IV) fluids

a. Heparin-locked IV access

2. Nifedipine

a. Nifedipine dose is continued at $20 \mathrm{mg}$ every $6 \mathrm{~h}$ or $10 \mathrm{mg}$ every $6 \mathrm{~h}$ if maternal systolic blood pressure is lower than $95 \mathrm{~mm} \mathrm{Hg}$

b. Nifedipine dose can be increased to every $4 \mathrm{~h}$ if palpable contractions are documented on every 6-h dosing

3. Pain management

a. Oral pain medications

4. Surveillance

a. Monitor uterine tocodynamometer only for patient complaints of, or nurse's assessment of irritability or contractions on examination

b. Fetal heart rate: checks every shift

c. Fetal adaptation and surgical complications: postoperative ultrasound evaluation

5. Diet

a. Regular diet

6. Maternal activity

a. Bilateral lower leg compression boots should be continued when in bed

b. (Expectation) Walking to the bathroom without assistance by end of the day

c. (Expectation) Showering using a shower chair

d. Patient assistance, only if needed 


\section{Key Points for Postoperative Day 3}

Dizziness and palpitations are common during the first $1-2$ weeks of nifedipine treatment

As such, need to be aware of this when begins to walk to the bathroom and during showers

Oral pain medications should be continued

Colace (100 mg twice daily) should be continued

Housing co-ordination and wheelchair plan for next day's discharge

Postoperative Day 4

1. Intravenous (IV) fluids

a. Discontinue IV access

2. Nifedipine

a. Nifedipine dose continues at $20 \mathrm{mg}$ every $6 \mathrm{~h}$ or $10 \mathrm{mg}$ every $6 \mathrm{~h}$ if maternal systolic blood pressure is lower than $95 \mathrm{~mm} \mathrm{Hg}$

b. Nifedipine dose can be increased to every $4 \mathrm{~h}$ if palpable contractions are documented on every 6 -h dosing

3. Pain management

a. Oral pain medications

4. Surveillance

a. Monitor uterine tocodynamometer only for patient complaints of, or nurse's assessment of irritability/ contractions on examination

b. Fetal heart rate: checks every shift

c. Fetal adaptation and surgical complications: postoperative ultrasound evaluation

5. Diet

a. Regular diet

6. Maternal activity

a. (Expectation) Walking to the bathroom without assistance

b. (Expectation) Showering using a shower chair

c. Patient assistance, only if needed

Key Points for Postoperative Day 4

Conditions for anticipated day of discharge

Contraction free

On regular diet

In good pain control

Ambulating without assistance

Has at least passed flatus

Has a normal ultrasound evaluation

Has a support person

Housing arranged

Discharge prescriptions (for 2 weeks)

Oral pain medications

Nifedipine

Daily prenatal vitamin and iron supplement

Colace (100 mg twice daily)

Review and document the advice on day of discharge

Scheduled for weekly follow-up ultrasound and prenatal visits

Activity restriction

Medication schedules

Signs and symptoms of postoperative complications (such as contractions, bleeding, fluid leakage, fever, wound complications, and decreased fetal movements)

Written discharge instruction given to the patient

Emergency calling number 


\section{References}

1 Adzick NS, et al: A randomized trial of prenatal versus postnatal repair of myelomeningocele. N Engl J Med 2011;364:993-1004.

2 Adzick NS: Open fetal surgery for life-threatening fetal anomalies. Semin Fetal Neonatal Med 2010;15:1-8.

3 Bowman RM, et al: Spina bifida outcome: a 25-year prospective. Pediatr Neurosurg 2001. 34:114-120.

4 Nehring WM, Faux SA: Transitional and health issues of adults with neural tube defects. J Nurs Scholarsh 2006;38:63-70.

5 Frey L, Hauser WA: Epidemiology of neural tube defects. Epilepsia 2003;44(suppl 3):4-13.

6 Zaganjor I, et al: Describing the prevalence of neural tube defects worldwide: a systematic literature review.PLoSOne 2016;11:e151586.

7 Atta CA, et al: Global birth prevalence of spina bifida by folic acid fortification status: a systematic review and meta-analysis. Am J Public Health 2016;106:e24-e34.

8 Owens JR, et al: 19-year incidence of neural tube defects in area under constant surveillance. Lancet 1981;2:1032-1035.

9 Liu J, et al: Prevalence and trend of neural tube defects in five counties in Shanxi province of Northern China, 2000 to 2014. Birth Defects Res A Clin Mol Teratol 2016;106:267-274.

10 Stone DH: The declining prevalence of anencephalus and spina bifida: its nature, causes and implications. Dev Med Child Neurol 1987;29:541-546.

11 Busby A, et al: Preventing neural tube defects in Europe: a missed opportunity. Reprod Toxicol 2005;20:393-402.

$12 \mathrm{Li}$ Z, et al: Extremely high prevalence of neural tube defects in a 4-county area in Shanxi Province, China. Birth Defects Res A Clin Mol Teratol 2006;76:237-240.

13 Allagh KP, et al: Birth prevalence of neural tube defects and orofacial clefts in India: a systematic review and meta-analysis. PLoS One 2015;10:e0118961.

14 Bower C, D'Antoine H, Stanley FJ: Neural tube defects in Australia: trends in encephaloceles and other neural tube defects before and after promotion of folic acid supplementation and voluntary food fortification. Birth Defects Res A Clin Mol Teratol 2009;85:269273.

15 Chan A, et al: Prevalence of neural tube defects in South Australia, 1966-91: effectiveness and impact of prenatal diagnosis. BMJ 1993;307:703-706

$16 \mathrm{Li} \mathrm{X}$, et al: Geographic and urban-rural disparities in the total prevalence of neural tube defects and their subtypes during 2006-2008 in China: a study using the hospital-based birth defects surveillance system. BMC Public Health 2013;13:161.

17 Zhang X, et al: Prevalence of birth defects and risk-factor analysis from a population-based survey in Inner Mongolia, China. BMC Pediatr 2012;12:125.
18 Dey AC, et al: Maternal and neonatal serum zinc level and its relationship with neural tube defects. J Health Popul Nutr 2010;28:343350.

19 Sarkar S, et al: Prevalence of congenital anomalies in neonates and associated risk factors in a tertiary care hospital in eastern India. J Clin Neonatol 2013;2:131-134.

20 Siripoonya P, Tejavej A: Congenital abnormalities in the early neonatal period: ten years incidence at Ramathibodi Hospital. J Med Assoc Thai 1980;63:544-547.

21 Dissaneevate S, et al: Congenital malformations of newborns at Songklanagarind Hospital. Songkla Med J 2003;21:267-276.

22 Wasant P, Sathienkijkanchai A: Neural tube defects at Siriraj Hospital, Bangkok, Thailand - 10 years review (1990-1999). J Med Assoc Thai 2005;88(suppl 8):S92-S99.

23 Jaruratanasirikul S, et al: Prevalence of neural tube defect in southern Thailand: a population-based survey during 2009-2012. Childs Nerv Syst 2014;30:1269-1275.

24 Borman GB, Smith AH, Howard JK: Risk factors in the prevalence of anencephalus and spina bifida in New Zealand. Teratology 1986; 33:221-230.

25 Borman B, Cryer C: The prevalence of anencephalus and spina bifida in New Zealand. J Paediatr Child Health 1993;29:282-288.

26 Tan KC, Ho NK: Current trends in the prevalence at birth of neural tube defects in Singapore. J Med Genet 1989;26:412-413.

27 Shi LM, et al: Prevalence of birth defects and parental work in Singapore live births from 1994 to 1998: a population-based study. Occup Med (Lond) 2002;52:325-331.

28 Laharwal MA, et al: Epidemiology of the neural tube defects in Kashmir Valley. Surg Neurol Int 2016;7:35.

29 Bhide P, et al: Systematic review of birth prevalence of neural tube defects in India. Birth Defects Res A Clin Mol Teratol 2013;97:437443.

30 Sood M, et al: Neural tubal defects in an east Delhi hospital. Indian J Pediatr 1991;58:363365.

31 Mahadevan B, Bhat BV: Neural tube defects in Pondicherry. Indian J Pediatr 2005;72:557559.

32 Grover N: Congenital malformations in Shimla. Indian J Pediatr 2000;67:249-251.

33 Malla BK: One year review study of congenital anatomical malformation at birth in Maternity Hospital (Prasutigriha), Thapathali, Kathmandu. Kathmandu Univ Med J (KUMJ) 2007; 5:557-560.

34 Zhang XH, Qiu LQ, Huang JP: Risk of birth defects increased in multiple births. Birth Defects Res A Clin Mol Teratol 2011;91:34-38.

35 Chen G, et al: Unusual patterns of neural tube defects in a high risk region of northern China. Biomed Environ Sci 2009;22:340-344.
36 Taksande A, et al: Congenital malformations at birth in Central India: a rural medical college hospital based data. Indian J Hum Genet 2010;16:159-163.

37 Li Y, et al: Analysis of the birth defects among 61,272 live born infants in Beijing. Beijing Da Xue Xue Bao 2009;41:414-417.

38 Liu J, et al: Prevalence of neural tube defects in economically and socially deprived area of China. Childs Nerv Syst 2007;23:1119-1124.

39 Chen BY, Hwang BF, Guo YL: Epidemiology of congenital anomalies in a populationbased birth registry in Taiwan 2002. J Formos Med Assoc 2009;108:460-468.

40 Imaizumi $Y$, et al: The prevalence at birth of cogenital malformations at a maternity hospital in Osaka City, 1948-1990. Jinrui Idengaku Zasshi 1991;36:275-287.

41 Seto T, et al: Trend of congenital anomalies over 20 years ascertained by populationbased monitoring in Ishikawa Prefecture, Japan. Congenit Anom (Kyoto) 2003;43:286293.

42 Kim MA, et al: Prevalence of birth defects in Korean livebirths 2005-2006. J Korean Med Sci 2012;27:1233-1240.

43 Boo NY, et al: Neural tube defects in Malaysia: data from the Malaysian National Neonatal Registry. J Trop Pediatr 2013;59:338-342.

44 Hoang T, et al: External birth defects in Southern Vietnam: a population-based study at the grassroots level of health care in Binh Thuan Province. BMC Pediatr 2013;13:67.

45 World Health Organization: Prevention and Control of Birth Defects in South-East Asia Region. Strategic Framework 2013-2017. New Delhi, World Health Organization, 2013.

46 Somasundaram K, Prathap K: Intra-uterine healing of skin wounds in rabbit foetuses. J Pathol 1970;100:81-86.

47 Verbeek RJ, et al: Fetal endoscopic myelomeningocele closure preserves segmental neurological function. Dev Med Child Neurol 2012; 54:15-22.

48 Araujo Junior E, et al: Procedure-related complications of open versus fetoscopic fetal surgery for treatment of spina bifida: systematic review and meta-analysis in the new era of intrauterine myelomeningocele repair. Ultrasound Obstet Gynecol 2016;48:151-160.

49 Bruner JP, et al: In utero repair of myelomeningocele: a comparison of endoscopy and hysterotomy. Fetal Diagn Ther 2000;15:8388.

50 Pedreira DA: Keeping it simple: a "two-step" approach for the fetoscopic correction of spina bifida. Surg Endosc 2010;24:2640-2641; author reply 2642-2643.

51 Kohl T, et al: Partial amniotic carbon dioxide insufflation during minimally invasive fetoscopic interventions seems safe for the fetal brain in sheep. J Laparoendosc Adv Surg Tech A 2010;20:651-653.
Prenatal Myelomeningocele Surgery in

Asia
Fetal Diagn Ther 2017;41:161-178

DOI: $10.1159 / 000452218$ 
52 Pedreira DA, et al: Fetoscopic single-layer repair of open spina bifida using a cellulose patch: preliminary clinical experience. J Matern Fetal Neonatal Med 2014;27:1613-1619.

53 Kohl T, et al: Percutaneous fetoscopic patch coverage of spina bifida aperta in the human - early clinical experience and potential. Fetal Diagn Ther 2006;21:185-193.

54 Pedreira DA, et al: Endoscopic surgery for the antenatal treatment of myelomeningocele: the CECAM trial. Am J Obstet Gynecol 2016; 214:111.e1-111.e11.

55 Araujo EJ, Tonni G, Martins WP: Outcomes of infants followed-up at least 12 months after fetal open and endoscopic surgery for meningomyelocele: a systematic review and metaanalysis. J Evid Based Med, Epub ahead of print.

56 Joyeux L, et al: Fetoscopic versus open repair for spina bifida aperta: a systematic review of outcomes. Fetal Diagn Ther 2016;39:161171.
57 Watanabe M, Kim AG, Flake AW: Tissue engineering strategies for fetal myelomeningocele repair in animal models. Fetal Diagn Ther 2015;37:197-205.

58 Watanabe M, et al: Complete tissue coverage achieved by scaffold-based tissue engineering in the fetal sheep model of myelomeningocele. Biomaterials 2016;76:133-143.

59 Akkermans J, et al: A worldwide survey of laser surgery for twin-twin transfusion syndrome. Ultrasound Obstet Gynecol 2015;45: 168-174.

60 Moldenhauer JS, et al: Fetal myelomeningocele repair: the post-MOMS experience at the Children's Hospital of Philadelphia. Fetal Diagn Ther 2015;37:235-240.

61 Moise KJ Jr, et al: Current selection criteria and perioperative therapy used for fetal myelomeningocele surgery. Obstet Gynecol 2016;127:593-597.

62 McDonnell GV, McCann JP: Issues of medical management in adults with spina bifida. Childs Nerv Syst 2000;16:222-227.

63 Zhang J, et al: Contemporary cesarean delivery practice in the United States. Am J Obstet Gynecol 2010;203:e326.e1-e326.e10.
64 Chan YM, et al: A survey of prenatal first-trimester aneuploidy screening among Hong Kong specialist obstetricians. Hong Kong Med J 2009;15:447-451.

65 Rowe R, et al: Offer and uptake of prenatal screening for Down syndrome in women from different social and ethnic backgrounds. Prenat Diagn 2008;28:1245-1250.

66 Dormandy E, et al: Low uptake of prenatal screening for Down syndrome in minority ethnic groups and socially deprived groups: a reflection of women's attitudes or a failure to facilitate informed choices? Int J Epidemiol 2005;34:346-352.

67 Brock JW 3rd, et al: Bladder function after fetal surgery for myelomeningocele. Pediatrics 2015;136:e906-e913.

68 Tulipan N, et al: Prenatal surgery for myelomeningocele and the need for cerebrospinal fluid shunt placement. J Neurosurg Pediatr 2015;16:613-620 